\title{
Spectroscopic Evidence for Mobilization of Amide Position Protons During CID of Model Peptide Ions
}

\author{
Samuel Molesworth, ${ }^{\text {a }}$ Christopher M. Leavitt, ${ }^{\mathrm{a}, *}$ Gary S. Groenewold, ${ }^{\mathrm{b}}$ \\ Jos Oomens, ${ }^{\mathrm{c}}$ Jeffrey D. Steill, ${ }^{\mathrm{c}}$ and Michael van Stipdonk ${ }^{\mathrm{a}}$ \\ ${ }^{a}$ Department of Chemistry, Wichita State University, Wichita, Kansas, USA \\ ${ }^{b}$ Chemical Sciences Group, Idaho National Laboratory, Idaho Falls, Idaho, USA \\ ${ }^{c}$ FOM Institute for Plasma Physics Rijnhuizen, Nieuwegein, The Netherlands
}

Infrared multiple photon dissociation (IRMPD) spectroscopy was used to study formation of $b_{2}^{+}$from nicotinyl-glycine-glycine-methyl ester (NicGGOMe). IRMPD shows that NicGGOMe is protonated at the pyridine ring of the nicotinyl group, and more importantly, that $b_{2}^{+}$from NicGGOMe is not protonated at the oxazolone ring, as would be expected if the species were generated on the conventional $b_{n}{ }^{+} / y_{n}{ }^{+}$oxazolone pathway, but at the pyridine ring instead. IRMPD data support a hypothesis that formation of $b_{2}^{+}$from NicGGOMe involves mobilization and transfer of an amide position proton during the fragmentation reaction. (J Am Soc Mass Spectrom 2009, 20, 1841-1845) (c) 2009 Published by Elsevier Inc. on behalf of American Society for Mass Spectrometry

$\mathrm{E}$ ffective application of tandem mass spectrometry, collision induced dissociation (CID), and bioinformatics for protein identification requires a clear understanding of peptide ion fragmentation mechanisms. Low-energy CID of protonated peptides promotes rearrangement reactions in which the added proton presumably migrates to the amide bond that is ultimately cleaved [1-12], as treated in the "mobileproton" (MP) [13-25], and "pathways in competition" (PIC) models of peptide dissociation [26]. Experimental studies have established that the C-terminus-containing $y_{n}{ }^{+}$fragments are truncated peptides [6, 27, 28], while the N-terminus-containing $b_{n}^{+}$and $a_{n}^{+}$species have substituted oxazolone ring and imine structures, respectively [4, $5,11,12,29,30]$.

Wavelength-selective infrared multiple photon dissociation (IRMPD) spectroscopy has recently been used to probe and confirm proposed structures of peptides and peptide dissociation products, with studies of the latter focusing primarily on $b_{n}{ }^{+}$and $a_{n}{ }^{+}$ions [11, 12, 29, 30]. Our group has designed model peptides and approaches to probe intramolecular migration of protons during peptide dissociation reactions [31, 32]. Versions of these model peptides are the subject of the present study, in which IRMPD was used to determine the structure of protonated nicotinic acid-glycine-glycine-

\footnotetext{
Address reprint requests to Professor M. Van Stipdonk, Department of Chemistry, Wichita State University, Wichita, KS 67260-0051, USA. E-mail: mike.vanstipdonk@wichita.edu

* Current address: Department of Chemistry, Yale University, 225 Prospect Street, P.O. Box 208107, New Haven, CT 06520-8107, USA.

A Portion of this work was presented at the 56th ASMS Conference on Mass Spectrometry and Allied Topics, Denver CO, 2008.
}

methyl ester (NicGGOMe), and the $b_{2}^{+}$fragment ions from NicGGOMe and benzoic acid-glycine-glycinemethyl ester (BzGGOMe). The pyridine ring of the nicotinic acid residue is used to sequester the "mobile" proton added to the peptide to produce $(\mathrm{M}+\mathrm{H})^{+}$, and inhibit migration to the site of intramolecular nucleophilic attack during fragmentation reactions. IRMPD spectroscopy provides strong evidence for the mobilization and migration of amide-position protons during dissociation reactions of model peptides.

\section{Experimental}

\section{Mass Spectrometry and IRMPD Spectroscopy}

CID experiments were performed using a ThermoFinnigan (San Jose, CA, USA) LCQ-Deca quadrupole ion trap (QIT) mass spectrometer. IRMPD spectra were collected using the FT-ICR mass spectrometer coupled to the beamline of the free electron-laser user facility (FELIX) infrared free electron laser [33-35]. Ions produced by electrospray ionization (ESI) were accumulated in a hexapole ion trap, and isolated and irradiated with FELIX for $2 \mathrm{~s}$ at a $5 \mathrm{~Hz}$ repetition rate over a wavelength range 5.6-10 $\mu \mathrm{m}(\sim 1000-1780$ $\mathrm{cm}^{-1}$ ): beyond $5.6 \mu \mathrm{m}$, there was a significant loss of laser power. Data acquisition and instrument control was accomplished using a modified version of the data system and software developed by Heeren and coworkers [36].

NicGGOMe and BzGGOMe were prepared by coupling nicotinic or hippuric acid to glycine methyl ester using a resin-bound carbodiimide (PS-Carbodiimide; 
Argonaut, Foster City, CA, USA), and used as $1 \mathrm{mM}$ solutions in $80 / 20$ methanol/water with $\sim 1 \%$ acetic acid added to aid protonation ESI produces abundant $(\mathrm{M}+\mathrm{H})^{+}$ions for both peptides. Adjusting the rf amplitude and the axial trapping voltage of the accumulation hexapole region allows formation of $b_{2}^{+}$by source CID.

CID (QIT) spectra generated from NicGGOMe and BzGGOMe are provided in supplemental information, Figure S-1, which can be found in the electronic version of this article. CID of protonated NicGGOMe and BzGGOMe produces predominately $b_{2}^{+}$. CID of $b_{2}^{+}$derived from either precursor produces $a_{2}^{+}$, and the same product ions generated upon resonant infrared irradiation with FELIX. To generate an IRMPD spectrum, $a_{2}^{+}$ fragment intensities were summed and divided by the total ion intensity at each wavelength, and linearly corrected for variations in the laser pulse energy.

\section{Density Functional Theory Calculations}

The Gaussian 03 set of programs [37] was used for all DFT calculations. A range of structures for protonated NicGGOMe, and $b_{2}^{+}$from NicGGOMe and BzGGOMe, were initially (fully) optimized at the HF/6-31g(d) level of theory, and then reoptimized at the B3LYP/6$31+g(d, p)$ and B3LYP/6-311+g(d,p) levels of theory. Because of the small size of the model systems, an intensive search of the peptide potential energy surface using molecular dynamics was not deemed necessary. Relative energies for all species were calculated by correcting B3LYP/6-311+g(d,p) total energies for zeropoint vibrational energy (ZPE) obtained from the unscaled frequencies determined at the same level of theory. Predicted IR spectra were generated at the B3LYP/6-311 $+\mathrm{g}(\mathrm{d}, \mathrm{p})$ level of theory and scaled by a factor of 0.98 , which is commonly used when comparing DFT and IRMPD data for peptides [29, 30, 32].

\section{Results and Discussion}

In Figure 1, the IRMPD spectrum of NicGGOMe is compared with (theoretical) spectra for the three lowest energy conformations predicted by DFT [(1a), pyridine ring protonated, (1b) and (1c) charge solvated structures]. Structures for several other minima are provided in Figure S-2, and electronic energies, zero-point energy corrections and relative energies in Table S-1 of the supporting information The spectrum predicted for the pyridine ring-protonated structure (Nic_RP_1, Figure S-2) agrees best with the experimental IRMPD spectrum; agreement between the spectra predicted for the "charge-solvated" conformations (Nic_OP_6 or Nic_ OP_7, Figure S-2) is poor.

The four lowest energy conformations for $b_{2}^{+}$from NicGGOMe are shown in Figure S-3; energies are provided in Table S-2. Calculations indicate that isomers of $b_{2}^{+}$protonated at the pyridine ring (Nic_b $\mathrm{b}_{2-} \mathrm{a}$ and Nic_b $b_{2}$ b, Figure S-3) are favored by ca. $6-7 \mathrm{kcal} /$

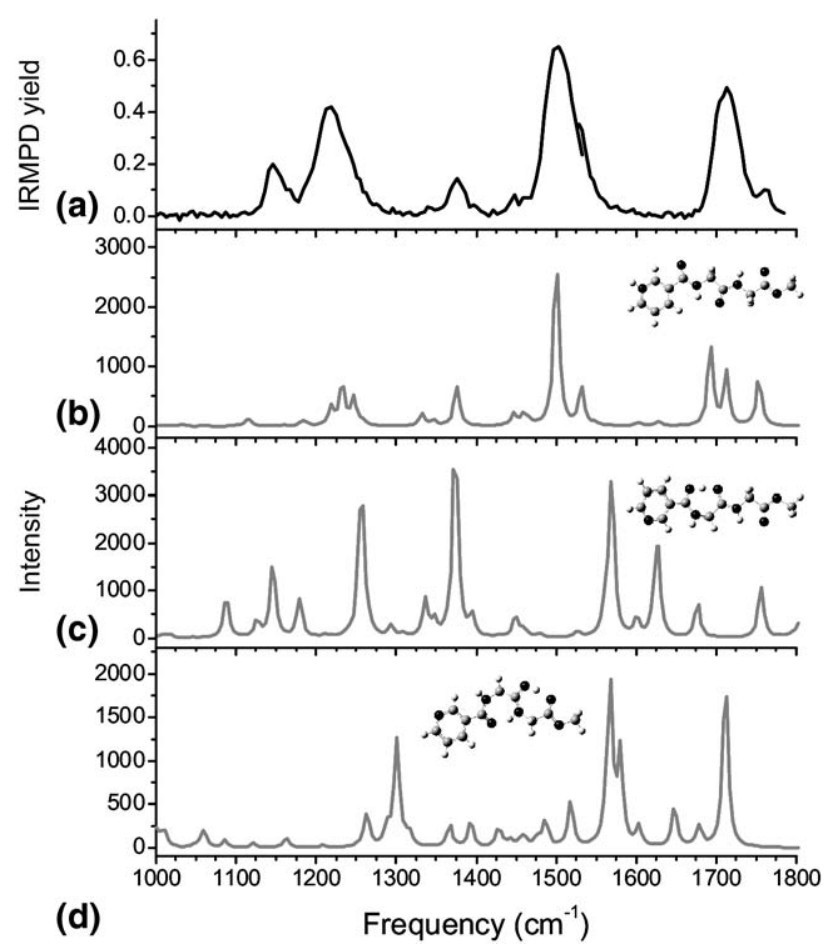

Figure 1. Experimental IRMPD spectrum of protonated Nic-GGOMe compared with calculated spectra for the three low-energy structures. (a) IRMPD spectrum; (b) pyridine ring protonated structure; (c) and (d) charge solvated, amide $\mathrm{C}=\mathrm{O}$ protonated structures. Predicted spectra are generated at the B3LYP/6-311+g(d,p) level of theory and are scaled by a factor of 0.98 .

mol over those protonated on the oxazolone ring (Nic_b ${ }_{2}$ c and Nic_b ${ }_{2}$ d, Figure S-3). The experimental IRMPD spectrum for $b_{2}^{+}$derived from NicGGOMe is compared to the theoretical IR spectra predicted for all four isomers in Figure S-4. In Figure 2, the IRMPD spectrum of $b_{2}^{+}$(Figure 2a) is compared with a blend (50:50) of the spectra predicted for the two pyridine protonated species (Nic_b $b_{2}$ a and Nic_b 2 b, Figure $2 b$ ), and the lowest energy isomer featuring a protonated oxazolone $\mathrm{N}$ atom (Nic_b $\mathrm{b}_{2} \mathrm{c}$, Figure 2c). Because of difficulty accessing the frequency region expected for the oxazolone $\mathrm{C}=\mathrm{O}$ stretch (ca. $1960 \mathrm{~cm}^{-1}$ ) due to low laser power, comparison is made between IRMPD and DFT in Figure 2 using the frequency range 1200-1700 $\mathrm{cm}^{-1}$. The predicted IR spectrum of the oxazoloneprotonated structure contains a diagnostic absorption near $1580 \mathrm{~cm}^{-1}$ for the latter ( $\mathrm{N}-\mathrm{H}$ bending mode) that is absent both for the spectrum predicted for the pyridine ring-protonated structure and in the IRMPD spectrum. As evident in Figure S-4, there is also good agreement between the IRMPD and DFT spectra for the Nic_b $b_{2} a$ and Nic_ $b_{2}-b$ in the region of the oxazolone $\mathrm{C}=\mathrm{O}$ stretch. The IRMPD spectrum of $b_{2}^{+}$generated from protonated BzGGOMe, a control peptide that lacks the $\mathrm{N}$ atom within the $\mathrm{N}$-terminal protecting group (Figure S-5 of the supporting information), is dominated by a feature at $1590 \mathrm{~cm}^{-1}$ that matches the position predicted for the $\mathrm{N}-\mathrm{H}$ bend in an oxazolone 


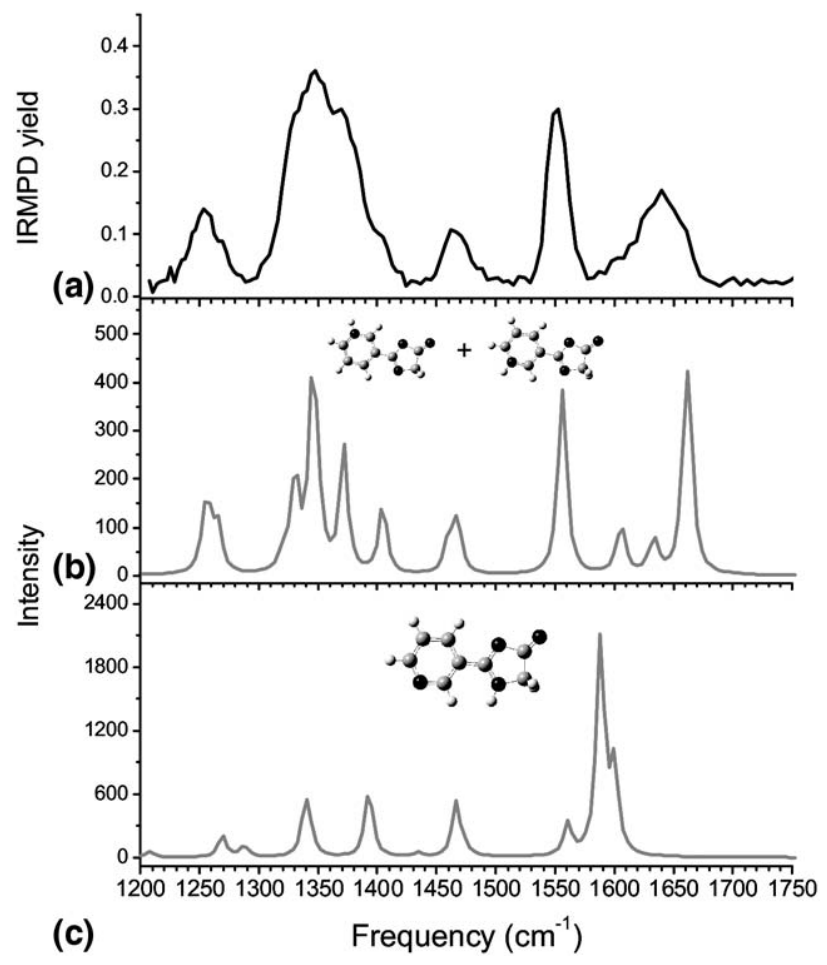

Figure 2. Experimental IRMPD spectrum of the $b_{2}^{+}$fragment of protonated NicGGOMe compared to calculated spectra. (a) IRMPD spectrum; (b) blend (50:50) of the spectra predicted for the pyridine ring protonated structures; (c) lowest energy oxazolone protonated structure. Predicted spectra are generated at the B3LYP/6$311+\mathrm{g}(\mathrm{d}, \mathrm{p})$ level of theory and are scaled by a factor of 0.98 .

protonated structure, thus ensuring that such a feature would be observed if present.

Two pathways can be proposed for generation of $b_{2}^{+}$ from NicGGOMe. The first would involve proton transfer and nucleophilic attack steps characteristic of the conventional $b_{n} / y_{n}$ oxazolone pathway $[9,10,26]$, as shown in Scheme 1. In this process, NicGGOMe is converted from a ring-protonated structure to a "charge-solvated" structure by transfer of a proton from the nicotinic acid ring to the proximate carbonyl. A second proton transfer to the neighboring amide-N atom then precedes intramolecular attack, with ring closure. This mechanism is not in accord with either the spectroscopic measurements or theory. Our DFT calculations indicate that the charge solvated structure is ca. $4-5 \mathrm{kcal} / \mathrm{mol}$ higher in energy than the pyridine ring protonated structure. Moreover, the IRMPD and calculated spectra displayed in Figure 1 indicate that gasphase NicGGOMe is protonated on the pyridine ring, with little evidence for a charge solvated structure. Migration of the proton from the pyridine ring to the amide carbonyl $\mathrm{O}$ atoms to populate the precursor species required in Scheme $\mathbf{1}$ is difficult to envision because of the meta- position of the $\mathrm{N}$ atom and the general rigidity of the nicotinyl group. In addition, no stable conformers were identified by DFT in which the $\mathrm{C}$-terminal amide $\mathrm{C}=\mathrm{O}$ group participates in an $\mathrm{H}$ bonding interaction with the protonated pyridine ring, and thus allow migration of the proton to the backbone (for example of closest approach, see Nic_OP_9 in Figure S-2 of the supporting information).

To account for generation of $b_{2}^{+}$from NicGGOMe, a second mechanism is proposed (Scheme 2 ) in which an amide position proton is mobilized and transferred to the departing glycine-methyl ester moiety. The reaction starts with proton transfer via a five-membered transition-state. This leads to charge separation, but the intermediate may be stabilized by intramolecular hydrogen bonding. Intramolecular attack forms the precursor to the oxazolone ring, which is completed upon proton transfer and scission of the amide linkage. This is supported by experiments in which the precursor peptide was first incubated in $\mathrm{D}_{2} \mathrm{O}$, and which show conclusively that the proton transferred is from an exchangeable site (Figure S-6), which for NicGGOMe must either be amide or the pyridine ring positions. The

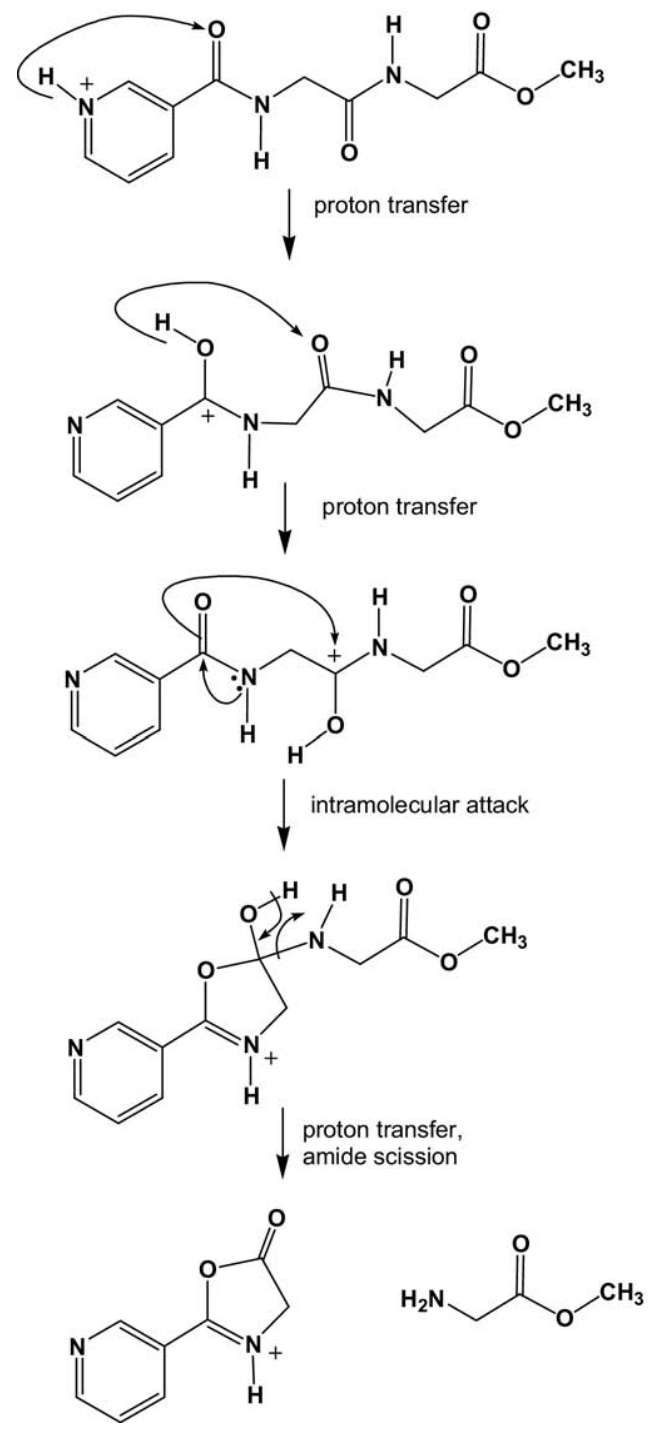

Scheme 1. Formation of $b_{2}^{+}$from protonated NicGGOMe through the conventional oxazolone pathway. Proton transferred to departing GOMe neutral originates at the pyridine ring $\mathrm{N}$ atom. 


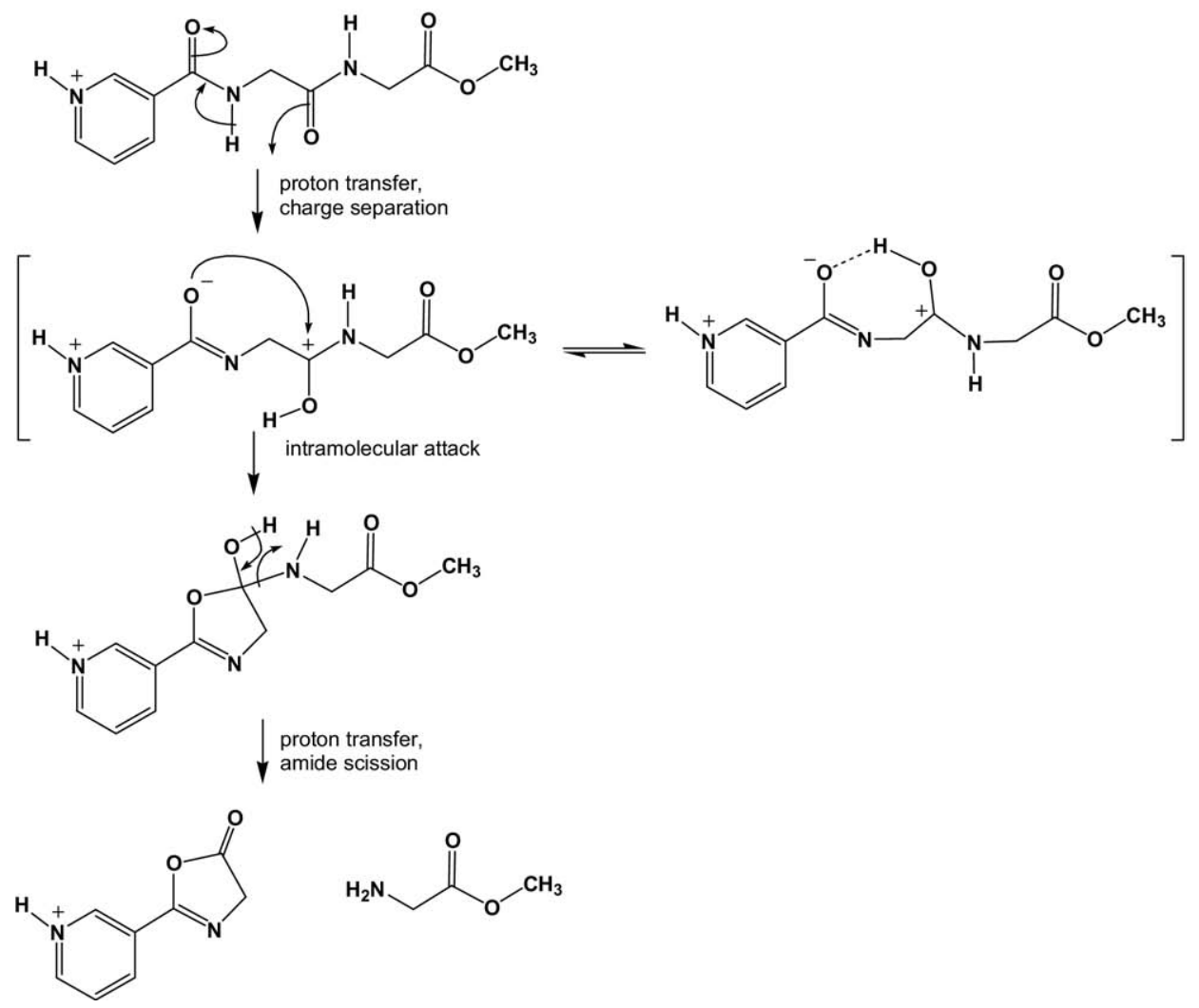

Scheme 2. Formation of $b_{2}^{+}$from protonated NicGGOMe through alternative pathway in which proton transferred to departing GOMe neutral originates at amide $\mathrm{N}$ atom.

alternative mechanism is consistent with the IRMPD results, which indicate that both NicGGOMe and $b_{2}^{+}$are protonated at the pyridine ring.

To summarize, IRMPD spectroscopy and DFT calculations unambiguously show that the $b_{2}^{+}$fragment ion from NicGGOMe is a substituted oxazolone protonated at the $\mathrm{N}$-atom of the pyridine ring. The fact that both ions are protonated on the pyridine ring provides evidence that $b_{2}^{+}$ions from NicGGOMe may be generated via a pathway that involves mobilization and transfer of amide position protons. We note that a low abundance ion corresponding to $b_{3}^{+}$is also generated from protonated NicGGOMe: this product is likely generated by a similar mechanism. Preliminary experiments show that $b_{2}^{+}$is the most abundant product generated from peptides with an $\mathrm{N}$-terminal betaine residue (Figure S-7, supporting information), species that have fixed charge sites without an "added" proton to migrate to the site of attack: for this particular peptide transfer of an amide position proton is required. In addition, CID of metal cationized versions of NicGGOMe and BzGGOMe produces prominent $\left(b_{2}-\right.$ $1+$ cat) ${ }^{+}$products (spectra not shown), which also must involve migration of amide position $\mathrm{H}$ atoms. Future work will include a theoretical survey of the reaction pathway to resolve the energetic details of the amide migration process, as well as a determination of whether a similar phenomenon is operative in the fragmentation of peptides that contain arginine residues.

\section{Acknowledgments}

M.V.S., S.M. and C.M.L. acknowledge support by the National Science Foundation (CAREER-0239800). S.M. also acknowledges financial support for his graduate work by Hospira, Inc. DFT calculations were performed at Wichita State University using resources of the High-performance Computing Center (HIPECC), a facility supported by the NSF under grants EIA-0216178 and EPS-0236913 and matching support from the State of Kansas and HIPECC. J.O. and J.D.S. acknowledge support by the Nederlandse Organisatie voor Wetenschappelijk Onderzoek (NWO). The excellent support by Dr. B. Redlich and others of the FELIX staff is gratefully acknowledged.

\section{Appendix A Supplementary Material}

Supplementary material associated with this article may be found in the online version at doi:10.1016/ j.jasms.2009.06.007.

\section{References}

1. Rodriquez, C. F.; Cunje, A.; Shoeib, T.; Chu, I. K.; Hopkinson A. C.; Siu, K. W. M. Proton Migration and Tautomerism in Protonated Triglycine. J. Am. Chem. Soc. 2001, 123, 3006-3012. 
2. Wu, R.; Mc Mahon, T. B. Infrared Multiple Photon Dissociation Spectroscopy as Structural Confirmation for GlyGlyGlyH ${ }^{+}$and AlaAlaAlaH ${ }^{+}$in the Gas Phase. Evidence for Amide Oxygen as the Protonation Site. J. Am. Chem. Soc. 2007, 129, 11312-11313.

3. Papayannopoulos, I. A. The Interpretation of Collision-Induced Dissociation Tandem Mass Spectra of Peptides. Mass Spectrom. Rev. 1995, 14, 49-73.

4. Yalcin, T.; Khouw, C.; Csizmadia, I. G.; Peterson, M. R.; Harrison, A. G. Why are B Ions Stable Species in Peptide Spectra? J. Am. Soc. Mass Spectrom. 1995, 6, 1165-1174.

5. Yalcin, T.; Csizmadia, I. G.; Peterson, M. B.; Harrison, G. The Structure and Fragmentation of $\mathrm{B}_{n}(n \geq 3)$ Ions in Peptide Spectra. J. Am. Soc. Mass Spectrom. 1996, 7, 233-242.

6. Nold, M. J.; Wesdemiotis, C.; Yalcin, T. Harrison, G. Amide Bond Dissociation in Protonated Peptides. Structures of the N-Terminal Ionic and Neutral Fragments. Int. J. Mass Spectrom. Ion Processes 1997, 164, 137-153

7. Paizs, B.; Lendvay, G.; Vékey, K. Suhai, S. Formation of $b_{2}^{+}$Ions from Protonated Peptides: An Ab Initio Study. Rapid Commun. Mass Spectrom. 1999, 13, 525-533.

8. Harrison, A. G.; Csizmadia, I. G.; Tang, T.-H. Structure and Fragmentation of $\mathrm{b}_{2}$ Ions in Peptide Mass Spectra. J. Am. Soc. Mass Spectrom. 2000, 11, 427-436.

9. Paizs, B.; Suhai, S. Combined Quantum Chemical and RRKM Modeling of the Main Fragmentation Pathways of Protonated GGG. II. Formation of $\mathrm{b}_{2}, \mathrm{y}_{1}$, and $\mathrm{y}_{2}$ Ions. Rapid Commun. Mass Spectrom. 2002, 16, 375-389.

10. Paizs, B.: Suhai, S. Towards Understanding the Tandem Mass Spectra of Protonated Oligopeptides. I: Mechanism of Amide Bond Cleavage. J. Am. Soc. Mass Spectrom. 2004, 15, 103-112.

11. Polfer, N. C.; Oomens, J.; Suhai, S.; Paizs, B. Spectroscopic and Theoretical Evidence for Oxazolone Ring Formation in Collision-Induced Dissociation of Peptides. J. Am. Chem. Soc. 2005, 127, 17154-17155.

12. Polfer, N. C.; Oomens, J.; Suhai, S.; Paizs, B. Infrared Spectroscopy and Theoretical Studies on Gas-Phase Protonated Leu-Enkephalin and Its Fragments: Direct Experimental Evidence for the Mobile Proton. J. Am. Chem. Soc. 2007, 120, 5887-5897.

13. Jones, J. L.; Dongré, A. R.; Somogyi, Á.; Wysocki, V. H. Sequence Dependence of Peptide Fragmentation Efficiency Curves Determined by Electrospray Ionization/Surface-Induced Dissociation Mass Spectrometry. J. Am. Chem. Soc. 1994, 116, 8368-8369.

14. Tsaprailis, G.; Nair, H.; Somogyi, Á.; Wysocki, V. H.; Zhong, W.; Futrell, J. H.; Summerfield, S. G.; Gaskell, S. J. Influence of Secondary Structure on the Fragmentation of Protonated Peptides. J. Am. Chem. Soc. 1999, $121,5142-5154$

15. Wysocki, V. H.; Tsaprailis, G.; Smith, L. L.; Breci, L. A. Mobile and Localized Protons: A Framework for Understanding Peptide Dissociation. J. Mass Spectrom. 2000, 35, 1399-1406.

16. Tsang, C. W.; Harrison, A. G. Chemical Ionization of Amino Acids. J. Am. Chem. Soc. 1976, 98, 1301-1308.

17. Harrison, A. G.; Yalcin, T. Proton Mobility in Protonated Amino Acids and Peptides. Int. J. Mass Spectrom. Ion Processes 1997, 165, 339-347.

18. Burlet, O.; Yang, C. Y.; Gaskell, S. J. Influence of Cysteine to Cysteic Acid Oxidation on the Collision-Activated Decomposition of Protonated Peptides: Evidence for Intraionic Interactions. J. Am. Soc. Mass Spectrom. 1992, 3, 337-344.

19. Cox, K. A.; Gaskell, S. J.; Morris, M.; Whiting, A. Role of the Site of Protonation in the Low-Energy Decompositions of Gas-Phase Peptide Ions. J. Am. Soc. Mass Spectrom 1996, 7, 522-531.

20. Summerfield, S. G.; Whiting, A.; Gaskell, S. J. Intraionic Interactions in Electrosprayed Peptide Ions. Int. J. Mass Spectrom. Ion Processes 1997, $162,149-161$.

21. Summerfield, S. G.; Cox, K. A.; Gaskell, S. J. The Promotion of $d$-Type Ions During the Low Energy Collision-Induced Dissociation of Some Cysteic Acid-Containing Peptides. J. Am. Soc. Mass Spectrom. 1997, 8, $25-31$.
22. Tang, X.; Boyd, R. K. An Investigation of Fragmentation Mechanisms of Doubly Protonated Tryptic Peptides. Rapid Commun. Mass Spectrom. $1992,6,651-657$

23. Tang, X.; Thibault, P.; Boyd, R. K. Fragmentation Reactions of MultiplyProtonated Peptides and Implications for Sequencing by Tandem Mass Spectrometry with Low-Energy Collision- Induced Dissociation. Anal. Chem. 1993, 65, 2824-2834.

24. Csonka, I. P.; Paizs, B.; Lendavy, G.; Suhai, S. Proton Mobility in Protonated Peptides: A Joint Molecular Orbital and RRKM Study. Rapid Commun. Mass Spectrom. 2000, 14, 417-427.

25. Paizs, B.; Csonka, I. P.; Lendvay, G.; Suhai, S. Proton Mobility in Protonated Glycylglycine and N-Formylglycylglycinamide: A Combined Quantum Chemical and RKKM Study. Rapid Commun. Mass Spectrom. 2001, 15, 637-647.

26. Paizs, B.; Suhai, S. Fragmentation Pathways of Protonated Peptides Mass Spectrom. Rev. 2004, 24, 508-548.

27. Polce, M. J.; Ren, D.; Wesdemiotis, C. Dissociation of the Peptide Bond in Protonated Peptides. J. Mass Spectrom. 2000, 35(12), 1391-1398.

28. Cordero, M. M.; Houser, J. J.; Wesdemiotis, C. The Neutral Products Formed During Backbone Fragmentations of Protonated Peptides in Tandem Mass Spectrometry. Anal. Chem. 1993, 65, 1594-1601.

29. Oomens, J.; Young S.; Molesworth, S.; van Stipdonk, M. Spectroscopic Evidence for an Oxazolone Structure of the $b_{2}$ Fragment Ion from Protonated Tri-alanine. J. Am. Soc. Mass Spectrom. 2009, 20, 334-339.

30. Yoon, S. H.; Chamot-Rooke, J.; Perkins, B. R.; Hilderbrand, A. E. Poutsma, J. C.; Wysocki, V. H. IRMPD Spectroscopy Shows that AGG Forms an Oxazolone $b_{2}^{+}$Ion. J. Am. Chem. Soc. 2008, 130, 17644-17645.

31. Bulleigh, K.; Howard, A.; Do, T.; Wu, Q.; Anbalagan, V.; Van Stipdonk, M. Investigation of Intramolecular Proton Migration in A Series of Model, Metal-Cationized Tripeptides Using In-Situ Generation of an Isotope Label. Rapid Commun. Mass Spectrom. 2006, 20, 227-232.

32. Van Stipdonk, M. J.; Kerstetter, D. R.; Leavitt, C. M.; Groenewold, G. S. Steill, J.; Oomens, J. Spectroscopic Investigation of H Atom Transfer in a Gas-Phase Dissociation Reaction: McLafferty Rearrangement of Model Gas-Phase Peptide Ions. Phys. Chem., Chem. Phys. 2008, 10, 3209-3221.

33. Oepts, D.; van der Meer, A. F. G.; van Amersfoort, P. W. The FreeElectron-Laser User Facility FELIX. Infrared Phys. Technol. 1995, 36297.

34. Polfer, N. C.; Oomens, J. Reaction Products in Mass Spectrometry Elucidated with Infrared Spectroscopy. Phys. Chem., Chem. Phys. 2007, 9, 3804-3817.

35. Valle, J. J.; Eyler, J. R.; Oomens, J.; Moore, D. T.; van der Meer, A. F. G.; von Helden, G.; Meijer, G.; Hendrickson, C. L.; Marshall, A. G.; Blakney, G. T. Free Electron Laser-Fourier Transform Ion Cyclotron Resonance Mass Spectrometry Facility for Obtaining Infrared Multiphoton Dissociation Spectra of Gaseous Ions. Rev. Sci. Instrum. 2005, 76, 023103.

36. Mize, T. H.; Taban, I.; Duursma, M.; Seynen, M.; Konijnenburg, M.; Vijftigschild, A.; Doornik, C. V.; Rooij, G. V.; Heeren, R. M. A. A Modular Data and Control System to Improve Sensitivity, Selectivity, Speed of Analysis, Ease of Use, and Transient Duration in an Externa Source FTICR-MS. Int. J. Mass Spectrom. 2004, 235, 243-253.

37. Frisch, M. J.; Trucks, G. W.; Schlegel, H. B.; Scuseria, G. E.; Robb, M. A.; Cheeseman, J. R.; Montgomery, J. A. Jr.; Vreven, T.; Kudin, K. N Burant, J. C.; Millam, M.; yengar, S. S.; Tomasi, J.; Barone, V.; Mennucci, B.; Cossi, M.; Scalmani, G.; Rega, N.; Petersson, G. A.; Nakatsuji, H.; Hada, M.; Ehara, M.; Toyota, K.; Fukuda, R.; Hasegawa, J.; Ishida, M.; Nakajima, T.; Honda, Y.; Kitao, O.; Nakai, H.; Klene, M.; Li, X.; J. E.; Knox, Hratchian, H. P.; Cross, J. B.; Bakken, V.; Adamo, C.; aramillo, J. Gomperts, R.; Stratmann, R. E.; Yazyev, O.; Austin, A. J.; Cammi, R.; Pomelli, C.; Ochterski, J. W.; Ayala, P. Y.; Morokuma, K.; Voth, G. A.; Salvador, P.; Dannenberg, J. J.; Zakrzewski, V. G.; Dapprich, S.; Daniels, A. D.; Strain, M. C.; Farkas, O.; Malick, D. K.; Rabuck, A. D.; Raghavachari, K.; Foresman, J. B.; Ortiz, J. V.; Cui, Q.; Baboul, A. G.; Clifford, S. Cioslowski, J.; Stefanov, B. B.; Liu, G.; Liashenko, A.; Piskorz, P.; Komaromi, I.; Martin, R. L.; Fox, D. J.; Keith, T.; Al-Laham, M. A.; Peng, C. Y.; Nanayakkara, A.; Challacombe, M.; Gill, P. M. W.; Johnson, B.; Chen, W.; Wong, M. W.; Gonzalez, C.; Pople, J. A. Gaussian 03, Rev. D. 01; Gaussian, Inc.: Wallingford, CT, 2004. 